\title{
Validity of data collected in BIOREG, the Austrian register for biological treatment in rheumatology: current practice of bDMARD therapy in rheumatoid arthritis in Austria
}

Bernhard Rintelen ${ }^{1,2^{*}}$, Jochen Zwerina ${ }^{3}$, Manfred Herold ${ }^{4}$, Franz Singer ${ }^{5}$, Johann Hitzelhammer ${ }^{6}$, Wolfgang Halder ${ }^{7}$, Gabriela Eichbauer-Sturm ${ }^{8}$, Rudolf Puchner ${ }^{9}$, Miriam Stetter ${ }^{10}$, Burkhard F. Leeb ${ }^{1,2,11}$ and on behalf of the BIOREG investigator group

\begin{abstract}
Background: The purpose of the present study was to check the validity of data collected in BIOREG, the Austrian register for biological treatment in rheumatology, and to elucidate eventual differences with respect to disease activity (DA) in patients with rheumatoid arthritis (RA) on established biological DMARDs (bDMARDs) before inclusion into the register (EST) and beginners at the time point of inclusion (NEW) after 1 year of treatment.

Methods: RA patients with a complete follow-up of 1 year in BIOREG were divided into EST and NEW and compared with respect to DA, remission rates, concomitant synthetic DMARDs (csDMARDs) and glucocorticoid therapy (GC) at baseline and after 1-year follow-up. Safety concerns are listed. Descriptive statistics are applied.

Results: For 346 RA patients (284 EST, 62 NEW) out of 970 RA patients included into BIOREG, a full data set for a 1year follow-up was available. No differences in DA were observed after 1 year as expressed by DAS28 or RADAl-5, and small differences as expressed by remission rates according to DAS28, RADAI-5 or Boolean criteria (namely approximately $1 / 2,1 / 3$ to $1 / 4$ and $1 / 4$ to $1 / 5$ of the patients respectively). Sixty-four adverse events (AEs) were noted in 56 (20\%) of EST and 20 in 19 (31\%) of NEW patients. Malignancy occurred in four patients. After 1 year, $48 \%$ of EST patients but only $16 \%$ of NEW patients were on bDMARD monotherapy.

Conclusion: Regarding DA, the date collected in BIOREG appeared to be valid. After 1 year of bDMARD therapy, all patients, whether EST or NEW, achieved a similar level of DA. AEs occurred more frequently during the early phase of bDMARD treatment. Austrian rheumatologists initiate bDMARD therapy in patients with lower disease levels than in other European countries, leading to high remission rates.
\end{abstract}

\section{Background}

BIOREG, the Austrian register for patients with chronic rheumatic diseases treated with biological agents, was established in 2010 [1]. Up to the time of the data report in October 2015, 970 patients suffering from rheumatoid arthritis (RA), 276 from psoriatic arthritis, 407 from

\footnotetext{
* Correspondence: bernhard.rintelen@stockerau.lknoe.at

${ }^{1}$ Lower Austrian State Hospital Stockerau, 2nd Department for internal

medicine, Lower Austrian Center for Rheumatology, Landstrasse 18,

Stockerau 2000, Austria

${ }^{2}$ Karl Landsteiner Institute for Clinical Rheumatology, Landstrasse 18,

Stockerau 2000, Austria

Full list of author information is available at the end of the article
}

spondylarthritis and 51 from other chronic rheumatic diseases such as systemic lupus erythematodes, juvenile arthritis, chronic inflammatory bowel disease and Still disease were included into the registry. The primary goal of the register is to document safety concerns, as well as disease activity (DA) and changes of therapy, and to collect socioeconomic data. Twenty Austrian centres currently take part in BIOREG (eight rheumatologists in private offices and 12 specialized rheumatology outpatient clinics in public or private hospitals in all nine federal states of Austria). BIOREG is a member of the European Network of Centres for Pharmacoepidemiology and Pharmacovigilance 
(ENEPP), is in close partnership with the Austrian Society for Rheumatology and Rehabilitation (ÖGR) and is supported by an unrestricted industrial grant. Data analysis is performed annually in September.

The intention of this study was to check the validity of the collected data, as well as to get insights into the "real-world" use of bDMARDs (biologic Disease Modifying Antirheumatic Drugs) in Austria. Therefore, we compared patients included into BIOREG when starting bDMARD therapy (NEW) with those on established bDMARD therapy (EST) at the time point of inclusion. Disease activity in general, remission rates, concomitant conventional synthetic DMARDs (csDMARDs), concomitant glucocorticoid therapy (GC) and adverse events were analysed at the time point of inclusion after 1 year. We hypothesized that, emanating from difference at inclusion, DA should be comparable in EST and NEW after 1 year of inclusion in BIOREG. Furthermore, for plausibility, we compared our results with other registers, e.g. the German register RABBIT [2].

\section{Methods}

To be included into this evaluation, it was a prerequisite that a full data set be available for the respective patients at the time point of inclusion and after 1 year of observation. We defined NEW patients as starting on a bDMARD at the time point of registration in BIOREG (+/- 30 days); all other patients were regarded as EST patients.

In all patients, the number of tender and swollen joints (TJ, SJ) based on the 28-joint count, the erythrocyte sedimentation rate in the first hour (ESR) and the patient's global assessment of the disease on a $100 \mathrm{~mm}$ visual analogue scale (VASGH), as well as the physician's global assessment of disease activity on a $100 \mathrm{~mm}$ visual analogue scale (VASPH), were available. The DAS28ESR was calculated [3], and additionally patient-related outcomes, such as the RADAI-5 [4] and the health assessment questionnaire disability index (HAQ-DI), were documented [5].

With respect to efficacy, remission rates according to the DAS28-ESR [6], the Boolean criteria (BC) on the basis of the 2011 ACR/EULAR remission criteria [7] and remission as defined by the RADAI- 5 disease activity categories [8] after 1 year were compared. In addition, concomitant therapies with csDMARDs as well as GC were evaluated, along with the percentage of patients receiving biological mono-therapy. With respect to tolerability, adverse events (AEs) and co-morbidities during the 1-year treatment period with bDMARDs were compared in both groups, analysed in relation to all patients with missing data. Primarily descriptive statistics were applied. Where appropriate, median values and the 25th to 75 th interquartile range or percentages were calculated. The deadline for inclusion into this study was the end of August 2015 (report dated October 2015).

All patients gave their informed consent before inclusion into BIOREG, which is treated as a prospective observational study. Collection of data is completely anonymous, using printed case report forms that are collected in an office for computerizing and analysing [1]. The central computer is not connected to the World Wide Web, to avoid data abuse. Data are collected sixmonthly (+/- 3 months). The ethical committee of Lower Austria has approved the study design of BIOREG (Reference number GS4-EK-085-2009).

\section{Results}

The records of 346 patients complied with the prerequisite of a complete data set, as described, at inclusion and after 1 year of follow-up (36\% of all in BIOREG included RA patients, EST $N=284$, NEW $N=62$ ).

As shown in the demographic data (Table 1), EST patients show a 5-year longer median disease duration than NEW patients; they are on bDMARD therapy for a median duration of 3.2 years; no age-related differences are found; rheumatoid factor and/or ACPA are found positive in $68 \%$ of the EST patients and in $55 \%$ of the NEW patients; and co-morbidities are recorded in $64 \%$ of the EST patients and in $73 \%$ of the NEW patients, respectively. In EST patients, these disorders most frequently comprise cardiovascular diseases, which account for $27 \%$, followed by dyslipidemia in $16 \%$, osteoporosis in $14 \%$, depression in $10 \%$ and diabetes in $9 \%$; the respective percentages for NEW patients are $42,16,10,15$ and $10 \%$. As expected proof of bDMARD treatment efficacy, EST patients have milder disease at inclusion than NEW patients, as expressed by the DAS28 and the RADAI-5 (mild versus moderate disease activity according to both scores), as well as by the HAQ-DI.

After 1 year, on the group level, both EST and NEW patients can be categorized as being in remission according to DAS28 and in a mild disease activity stage according to the RADAI-5 (Table 2). Accordingly, NEW patients experienced a good EULAR response [9] and a significant response according to the RADAI-5 [10]. There was no significant change on either score in EST patients. Regarding remission as measured by the DAS28, the RADAI-5 and the BC, after the 1-year observation period, more than half of the patients were found in DAS28, approximately $27-36 \%$ in RADAI-5 and 21$26 \%$ in remission according to the $\mathrm{BC}$, respectively (Table 3). Additionally, no differences in HAQ-DI-scores were observed (Table 2).

With respect to concomitant treatment at the time point of inclusion into BIOREG, a smaller percentage of patients receiving csDMARDs and GC in the EST group 
Table 1 Demographics of RA patients included in BIOREG at baseline (if not otherwise indicated, median (25th and 75th percentile))

\begin{tabular}{|c|c|c|c|}
\hline & All pts & EST & New \\
\hline $\mathrm{n}$ & 970 & 284 & 62 \\
\hline Age (years) & $\begin{array}{l}58.0 \\
(50.0 ; 68.0)\end{array}$ & $\begin{array}{l}59.0 \\
(48.0,67.0)\end{array}$ & $\begin{array}{l}58.0 \\
(47.0,70.0)\end{array}$ \\
\hline Disease duration (years) & $\begin{array}{l}8.0 \\
(4.0,14.0)\end{array}$ & $\begin{array}{l}9.00 \\
(5.0,14.0)\end{array}$ & $\begin{array}{l}4.00 \\
(1.00,9.00)\end{array}$ \\
\hline Gender \% female & 77.3 & 78.4 & 77.4 \\
\hline RF pos $\%$ & $\begin{array}{l}69.3 \\
(n=894)\end{array}$ & $\begin{array}{l}68.0 \\
(n=264)\end{array}$ & $\begin{array}{l}54.8 \\
(n=59)\end{array}$ \\
\hline ACPA pos $\%$ & $\begin{array}{l}47.6 \\
(n=633)\end{array}$ & $\begin{array}{l}50.0 \\
(n=193)\end{array}$ & $\begin{array}{l}37.1 \\
(n=46)\end{array}$ \\
\hline $\begin{array}{l}\text { Duration of bDMARD treatment } \\
\text { prior inclusion (years) }\end{array}$ & $\begin{array}{l}1.99 \\
(0.22,5.18)\end{array}$ & $\begin{array}{l}3.22 \\
(1.53,6.02)\end{array}$ & na \\
\hline DAS28 & $\begin{array}{l}3.26 \\
(2.24,4.20)\end{array}$ & $\begin{array}{l}2.67 \\
(1.99,3.70)\end{array}$ & $\begin{array}{l}4.46 \\
(3.77,5.35)\end{array}$ \\
\hline RADAI-5 & $\begin{array}{l}3.2 \\
(1.6,4.8)\end{array}$ & $\begin{array}{l}2.6 \\
(1.2,4.4)\end{array}$ & $\begin{array}{l}4.4 \\
(3.2,6.2)\end{array}$ \\
\hline HAQ-DI & $\begin{array}{l}0.75 \\
(0.25,1.25)\end{array}$ & $\begin{array}{l}0.63 \\
(0.13,1.19)\end{array}$ & $\begin{array}{l}1.00 \\
(0.63,1.38)\end{array}$ \\
\hline GC \% & 35.9 & 25.0 & 66.1 \\
\hline cSDMARD \% & 64.6 & 56.0 & 83.9 \\
\hline
\end{tabular}

Abbreviations: ACPA Anti Citrullinated Peptide Antibodies, bDMARD biological DMARD, csDMARD concomitant conventional synthetic DMARD, DAS28 Disease Activity Score using ESR out of 28 joints, ESR erythrocyte sedimentation rate, EST pts with established bDMARD treatment before inclusion in BIOREG of whom a full data set as described is viable, GC concomitant glucocorticoid treatment, $H A Q-D I$ Health Assessment Questionnaire Disability Index, $N$ number of patients, $N A$ not applicable, NEW pts included in BIOREG with start of biologic treatment \pm 30 days of whom a full data set as described is viable, PTS patients, RA rheumatoid arthritis, RADAl-5 Rheumatoid Arthritis Disease Activity Index-5, RF Rheumatoid Factor

were found compared to the NEW patients (Table 3), as expected. Forty-four percent of the EST patients took no csDMARDs, while only $16 \%$ of the NEW patients were on monotherapy with a biological drug. In EST patients, the most frequently applied csDMARD was Methotrexate (MTX) in $47 \%$, followed by Leflunomide (LEF) in $6 \%$, Sulphasalazine (SSZ) in $2 \%$, and in $2 \%$ combinations of these three csDMARDs. In the NEW group, the numbers were $63 \%$ MTX, 16 \% LEF, 2 \% SSZ and $2 \%$ combination, respectively.
After 1 year of treatment, csDMARD therapy was stopped in $4 \%$ of the EST patients and in $16 \%$ of the NEW patients. At the 1-year follow-up visit, 25 patients (7.2 \% of all patients; EST 17 (6\%), NEW 8 (13\%)) had no concomitant bDMARD considering an accepted drug-free period of two recommended application intervals. Causes for decanting bDMARDs in EST patients were remission according DAS28 and/or CDAI and/or RADAI-5, the patient's wish and fear of AEs. In the eight NEW patients, the reasons were intolerance, bDMARD ineffectivity, the patient's wish and, in one case, newly

Table 2 Changes of disease activity and HAQ-DI in EST and NEW patients (median (25th and 75th percentile))

\begin{tabular}{|c|c|c|c|c|}
\hline & \multicolumn{2}{|l|}{ EST $(n=284)$} & \multicolumn{2}{|l|}{$\operatorname{NEW}(n=62)$} \\
\hline & baseline & after 1 year & baseline & after 1 year \\
\hline DAS28 & $2.67(1.99,3.70)$ & $2.58(1.80,3.45)$ & $4.46(3.77,5.35)$ & $2.43(1.54,3.57)$ \\
\hline DAS28 Diff & & $0.18(-0.47,0.87)$ & & $1.92(0.65,2.99)$ \\
\hline RADAI-5 & $2.6(1.2,4.4)$ & $2.2(1.0,4.0)$ & $4.4(3.2,6.2)$ & $2.4(1.2,3.8)$ \\
\hline RADAl-5 Diff & & $0.2(-0.5,1.2)$ & & $2.0(0.6,3.4)$ \\
\hline $\mathrm{HAQ}$ & $0.63(0.13,1.19)$ & $0.63(0.13,1.13)$ & $1.00(0.63,1.38)$ & $0.50(0.13,1.25)$ \\
\hline HAQ Diff & & $0.00(-0.13,0.25)$ & & $0.38(0.00,0.63)$ \\
\hline
\end{tabular}

Abbreviations: DAS28 Disease Activity Score using ESR out of 28 joints, DIFF Difference to baseline after 1 year follow up, ESR Erythrocyte Sedimentation Rate, EST pts with established bDMARD treatment before inclusion in BIOREG of whom a full data set as described is viable, HAQ-DI Health Assessment Questionnaire Disability Index, $N$ number of pts, NEW pts included in BIOREG with start of biologic treatment \pm 30 days of whom a full data set as described is viable, PTS patients, RADAl-5 Rheumatoid Arthritis Disease Activity Index-5 
Table 3 Percentages of remission at baseline and 1-year follow-up and percentages of concomitant csDMARD and GC therapy in EST and NEW patients

\begin{tabular}{lcccc}
\hline & \multicolumn{2}{c}{ EST $n=284$} & & NEW $n=62$ \\
\cline { 2 - 3 } & baseline & after 1 year follow up & baseline & after 1 year follow up \\
\hline DAS28 remission \% & 47.2 & 51.1 & 3.6 & 53.2 \\
RADAl-5 remission \% & 31.3 & 36.3 & 1.6 & 27.4 \\
BC remisson \% & 21.1 & 26.1 & 1.6 & 21.0 \\
GC\% & 25.0 & 27.8 & 66.1 & 48.4 \\
CSDMARD \% & 56.0 & 51.8 & 83.9 & 67.7 \\
bDMARD \% & 100.0 & 94.0 & na & 87.1 \\
\hline
\end{tabular}

Abbreviations: BC Boolean criteria, bDMARD biologic DMARD, cSDMARD conventional synthetic DMARD, DAS28 Disease Activity Score using ESR out of 28 joints, ESR Erythrocyte sedimentation rate, EST pts with established bDMARD treatment before inclusion in BIOREG of whom a full data set as described is viable, GC glucocorticoid; na not applicable, NEW pts included in BIOREG with start of biologic treatment \pm 30 days; pts patients, RADAl-5 Rheumatoid Arthritis Disease Activity Index-5

diagnosed prostate cancer. Just 17 of all these patients were on csDMARD therapy (9 EST, 8 NEW).

With respect to concomitant GCs, considerable differences between the two groups persisted. Whereas in the EST group $25 \%$ of the patients were on GCs at inclusion and $28 \%$ after 1 year, the frequency of GC users in NEW patients was notably greater, namely $66 \%$ at entry and $48 \%$ after 1 year.

After 1 year, 64 AEs were observed in 56 EST patients (20\% of all EST patients) and 20 AEs in 19 NEW patients (31\%) (Table 4); in all available records after 1 year of observation $(n=511)$, AEs appeared to occur in a total of $27 \%$ of patients. Analysis of the recorded AEs of EST and NEW patients in comparison to all reported AEs in RA patients after 1 year in BIOREG, showed that infections in several locations were most frequent in both groups and comparable to all reported AEs (approximately $40 \%$ ). Mostly upper and lower respiratory tract infections (40\% of reported infections) occurred, followed by common colds (17\%), urinary tract infections (12\%), herpetic infections (12\%), encapsulated infections such as septic arthritis or abscess (7 \%), gastrointestinal infections (7 \%) and others (5\%). Local drug reactions were much more common in NEW than in EST patients. No opportunistic infection was reported.

The proportion of serious adverse events (SAEs) was higher in EST than in NEW patients, approximately $50 \%$ of all reported AEs in EST and $20 \%$ in NEW patients, respectively. Fifty-four percent of the SAEs in EST patients and $25 \%$ in NEW patients were infections; malignant diseases occurred in four patients (three in EST patients: relapse of breast cancer, B-cell lymphoma and thyroid cancer; one in NEW patients: prostate cancer). Another two reports of malignant diseases were

Table 4 Adverse events during first year of observation (+/- 3 months). Adverse events reported fewer than three times are not listed, except that there were at least three reported adverse events in one group of patients. (Number of reported cases (in $\mathrm{N}$ of patients), \% of all reported adverse events). The last two columns describe adverse events recorded in all patients included in BIOREG RA-group with completed 1-year observation $(n=511)$

\begin{tabular}{|c|c|c|c|c|c|c|}
\hline \multirow[b]{2}{*}{ All } & \multicolumn{2}{|c|}{ EST (in $19.7 \%$ of pts) } & \multicolumn{2}{|c|}{ NEW (in $30.7 \%$ of pts) } & \multicolumn{2}{|c|}{ All RA pts in BIOREG with one year of observation (in $26.8 \%$ of pts) } \\
\hline & $64(56)$ & $100 \%$ & $20(19)$ & $100 \%$ & $153(137)$ & $100 \%$ \\
\hline SAE & $31(23)$ & $48.4 \%$ & $4(4)$ & $20.0 \%$ & $72(58)$ & $47.1 \%$ \\
\hline Infections & $25(23)$ & $39.1 \%$ & $8(8)$ & $40.0 \%$ & $60(56)$ & $39.2 \%$ \\
\hline Ulcerative skin lesions & $4(4)$ & $6.3 \%$ & $1(1)$ & $5.0 \%$ & $6(6)$ & $3.9 \%$ \\
\hline Malignant diseases & $3(3)^{a}$ & $4.7 \%$ & $1(1)^{b}$ & $5.0 \%$ & $6(6)^{c}$ & $3.9 \%$ \\
\hline Ophthalmic diseases & $3(3)$ & $4.7 \%$ & 0 & & $7(7)$ & $4.6 \%$ \\
\hline Thrombotic diseases & $3(3)$ & $4.7 \%$ & $1(1)$ & $5.0 \%$ & $4(4)$ & $2.6 \%$ \\
\hline Intolerance of biologic drug & $1(1)$ & $1.6 \%$ & $3(3)$ & $15.0 \%$ & $9(9)$ & $5.9 \%$ \\
\hline Vertigo & $3(2)$ & $4.7 \%$ & 0 & & $3(2)$ & $2.0 \%$ \\
\hline Others & $22(17)$ & $34.4 \%$ & $6(6)$ & $30.0 \%$ & $58(55)$ & $37.9 \%$ \\
\hline
\end{tabular}

Abbreviations: EST pts with established bDMARD treatment before inclusion in BIOREG of whom a full data set as described is viable, NEW pts included in BIOREG with start of biologic treatment \pm 30 days of whom a full data set as described is viable, PTS patients, RA rheumatoid arthritis, SAE serious adverse event

a relapse of breast cancer, B-cell lymphoma, thyroid cancer

${ }^{\mathrm{b}}$ prostate cancer

c as listed plus colorectal cancer and lung cancer 
detected in all viable records of RA patients after 1 year of observation (one case of colorectal cancer and one of lung cancer). Thus, in summary, neither a higher occurrence rate nor organ or tumor specificity of malignancies was revealed. No fatal casualties were reported.

\section{Discussion}

As expected, treatment of RA patients with bDMARDs proved to be effective in EST and NEW patients. NEW patients, in whom bDMARD therapy was started in moderate disease activity, achieved remission or low disease activity according to the DAS28 and the RADAI-5 after 1 year of observation, while EST patients remained stable in remission or low disease activity. After 1 year of observation, both EST and NEW patients achieved comparable DA, supporting the validity of the BIOREG data.

Remarkably high percentages of patients in remission were observed, not only according to the DAS28 (more than $50 \%$ in both groups) or to the RADAI-5 (approximately $27 \%$ in EST-and $36 \%$ in NEW patients), but also according to the $\mathrm{BC}$ ( $26 \%$ of the patients in the EST group, $21 \%$ in the NEW group). The varying rates of patients in remission, depending upon the definition applied, are well known [11]; however, other reports dealing with remission rates do not show as high rates as presented here $[12,13]$. One plausible reason for this may be that biological treatment in Austria is initiated in patients with milder disease than in other countries [14]. Better outcomes in milder than higher diseased patients are underlined by a recent study conducted in a fivecentre Norwegian register [15], as well as in the German register RABBIT, which recorded a 30 \% DAS28 remission rate when bDMARD therapy was started in moderate DA [16].

NEW patients' median disease activity according to the DAS28 before starting bDMARDs is somewhat lower in BIOREG compared to other European bDMARD registries (4.13 compared to 4.2-6.6), while median HAQ-DI scores are in a comparable range (1.0 vs $0.8-$ 1.9) [14]. bDMARDs in RA in Austria are restricted to patients having failed to thrive on at least one csDMARD (preferably MTX), and only rheumatologists are licensed for their prescription [17]. Although this may suggest a more liberal prescription of bDMARDs in Austria than in other European countries, initiation of bDMARDs in Austria follows the relevant EULAR recommendations [18].

Starting bDMARDs in moderately active diseased patients showed somewhat better numerical outcomes as measured by different instruments than commencing at a high disease activity level $[16,19]$. Regarding all patients after 12 months since BIOREG inclusion $(n=511)$, the median DAS28 was at the upper limit of remission (2.60 (25th and 75th percentile 1.80; $3.45)$ ) and the median RADAI- 5 was in the mild disease activity range $(2.2(1.0 ; 3.6))$, indicating efficacy when assessed by a composite index and by a patientreported outcome. This result may also be seen as an indicator that the patients included into this observation may be representative for all RA patients on the register.

As expected, in more NEW patients AEs were recognized during their first year of treatment with bDMARDs than in EST patients. Those AEs were mostly injection site reactions. Although NEW patients show higher disease activity, more frequently receive a higher amount of GC and csDMARDs and have more concomitant diseases, such as cardiovascular diseases, compared to EST patients, no more infectious complications were observed than in the EST group [20]. This finding may be in part due to the relatively short median exposure to bDMARDs in the EST group, namely 3 years, compared to an observation in the German register RABBIT, where 3 years was the cut-off to be regarded as "new on the drug" [21]. Compared with the RABBIT register, on which $13 \%$ of the included patients experienced an infection in the first year of observation (out of them $6 \%$ received a csDMARD without bDMARD), a similar overall percentage of infection of $11.7 \%$ in all available AEs reports after 1 year in BIOREG is reported [22]. However, there remains a discrepancy in the valuation of seriousness: whereas in BIOREG $53 \%$ of these infections are indicated as serious in all available AE reports (54 \% in EST, $25 \%$ in NEW), in the RABBIT register this percentage is $26 \%$ [22], which may be founded on different therapeutic strategies concerning infections. NEW patients fulfil the criterion in the RABBIT register, where patients are included at the start of bDMARD therapy, whereas EST patients in BIOREG are on bDMARD therapy for a median 3.2 years. Since most reports about this issue conclude that serious infections are most likely during the first years of bDMARD therapy and are associated with age, co-morbidities, concomitant GC use, high-dose bDMARD, previous treatment with CsDMARD and disability [23-26], further evaluations of this finding seem necessary to elucidate this discrepancy.

The most striking differences between the EST and NEW patient groups were related to concomitant treatment. EST patients took GCs (approximately $25 \%$ ) and csDMARDs (almost $50 \%$ ) much less frequently than NEW patients at the beginning, as well as after 1 year. This also mirrors the general intention to reduce the amount of medication in cases of successful treatment with bDMARDs. The overall use of GCs in the biological era is decreasing, although it is still high in clinical practice, at about $50 \%$ on average [27]. Compared to more than $70 \%$ GC co-treated patients in 
the German RABBIT register, concomitant GC use in NEW BIOREG patients was found to be comparable, namely $66 \%$ at baseline [28]. GCs are an important factor for co-morbidities in RA patients [29, 30], not only for infections but also for conditions such as osteoporosis, diabetes, cardiovascular diseases or skin atrophy. A fortiori, around $25 \%$ of GC users in the EST patients give hope that the use of GCs may be reduced in the future and underlines the effectiveness of bDMARD therapy.

At baseline, $44 \%$ of the EST patients and $16 \%$ of NEW patients received their bDMARD in monotherapy. In line with this finding, csDMARD therapy was stopped during the 1-year observation in $4 \%$ of the EST patients and in $16 \%$ of the NEW patients. An evaluation of all RA patients included in BIOREG revealed approximately $40 \%$ of patients receiving bDMARDs as monotherapy at baseline. The percentage of RA patients on bDMARD monotherapy seems to increase with time of treatment [31], underlining the intention of Austrian rheumatologists to optimize therapy by reducing GCs and csDMARDs and keeping the patient on the ultimately effective drug after having achieved the treatment goal. In the case of treatment success, Austrian rheumatologists follow the EULAR recommendations for adopting therapy when the treatment target is reached [18]. bDMARD monotherapy seems not to be exceptional in Europe, even though lower rates are commonly reported $(19-27 \%)$ [32, 33].

In patients with two or more csDMARD failures, the addition of a bDMARD doubles the chance of achieving remission compared with switching to a csDMARD [16]. In the report from the RABBIT register, high remission rates (DAS28 remission: 30.6 \%; ARA remission: $16.9 \%$ ) were observed in bDMARD patients with moderate disease activity according to the DAS28 at the start of treatment. These rates decreased to $8.5 \%$ in patients with DAS28 $>6$ at the time point of starting bDMARD [16]. These findings underline those derived from BIOREG. Not adding a csDMARD as a double- or triple-therapy, which has also been shown to be clinically effective $[34,35]$ with no difference in loss of work [36] but higher drop-out rates in the combination csDMARD groups, is an expensive approach [37]. In BIOREG, only $2 \%$ of EST and NEW patients were on a combination of csDMARDs when starting the bDMARD. A 1-year course of therapy with a bDMARD in Austria costs $€ 14,300-€ 20,000$, depending upon the drug and the dosage and administration [38]. Austria may be classed among countries with a liberal prescription policy [39]. However, a Treat to Target principle, with consecutive bDMARD after two csDMARD failures, seems to be cost effective after 2 years of treatment [40]. In addition, it should be considered that patients in BIOREG were treated for a median 6 years in EST and 4 years in NEW patients with several csDMARDs. Since bDMARDs are expensive and carry risks of adverse events, trials have been conducted with stopping TNF $\alpha$-blockers [41] or tapering them down when remission or stable low disease activity has been achieved [42]. Decanting TNFo-blockers shows worse clinical outcome than continuing, whereas cautious dose reduction at least for Etanercept or Adalimumab could be regarded a valuable alternative.

This study has limitations, the most important being the small number of NEW patients, as a result of the intention to include only patients with a full dataset available for a longitudinal study on tolerability and disease activity and therefore to avoid missing data [43]. Since BIOREG includes patients irrespective of the date of their initiation on bDMARDs, this disparity is an unavoidable drawback. Therefore, the presented data may give insights into the use of bDMARDs in Austria, but the section referring to the seriousness of AEs in particular has to be regarded with caution.

\section{Conclusion}

In summary, this first evaluation of data extracted from BIOREG, the register for bDMARDs in Austria, indicates successful RA treatment with bDMARDs in Austria at reasonable tolerability. Validity of the data could be evidenced by showing NEW patients at comparable disease activity as EST patients after 1 year of bDMARD therapy. Plausibility is indicated by comparison of the results with the RABBIT register, with one exception, namely the high rate of serious AEs in the form of infections in EST patients. Starting bDMARD at lower disease activity than in other European countries is possibly accompanied by higher remission rates, not only expressed by DAS28 or BC but also indicated by a patient-reported outcome, the RADAI-5, and higher rates of bDMARD monotherapy. This fact may imply more cost-intensive treatment while suggesting the possibility of better outcomes for patients. Additionally, after having achieved the treatment goal, it appears to be general practice in Austria to primarily reduce or even stop treatment with csDMARDs and GCs, while keeping patients on bDMARDs to maintain the therapeutic success.

\footnotetext{
Abbreviations

ACPA, Anti Citrullinated Peptide Antibodies; AE, adverse event; BC, Boolean remission criteria according to the 2011 ACR/EULAR remission criteria; CRF, Case report form; DA, disease activity; bDMARD, biological DMARD; csDMARD,

concomitant conventional synthetic DMARD; DAS28, Disease Activity Score using ESR out of 28 joints; ESR, erythrocyte sedimentation rate; EST, patients with established bDMARD treatment before inclusion in BIOREG, for whom a full data set as described is viable; GC, concomitant glucocorticoid treatment; HAQ-DI, Health Assessment Questionnaire Disability Index; LEF, Leflunomide; MTX methotrexate; N, number of patients; NA, not applicable; NEW, patients included in BIOREG with start of biological treatment \pm 30 days, for whom a full data set as described is viable; RA, rheumatoid arthritis; RADAI-5, Rheumatoid Arthritis Disease Activity Index-5; RF, Rheumatoid Factor; SSZ, Sulphasalazine; SJ, swollen joint; TJ, tender joint; VASGH, patient's global assessment of the disease on a $100 \mathrm{~mm}$ visual analogue scale; VASPH, physician's global assessment of disease activity on a $100 \mathrm{~mm}$ visual analogue scale
} 


\section{Acknowledgments}

The authors cordially thank Mr Andreas Schimetta (ASOKLIF) for collecting the BIOREG-case report forms, as well as the data processing. We wish to express our deepest gratitude to all other members of the BIOREG investigator group, Elke Böttcher MD, Lothar Boso MD, Hans Peter Brezinschek MD PhD, Attila Dunky MD PhD, Gabriele Eberl MD, Vera Ferincz MD, Markus Gaugg MD, Gudrun Lechner MD, Harsono TH Mai MD, Erich Mur MD PhD, Monika Mustak-Blagusz MD, Valerie Nell-Duxneuner MD PhD, Andrea Österbauer MD, Peter Petera MD, Judith Sautner MD, Martin Steindl MD, Otto Stummer LLD, Gerhard Teich MD, Wolfgang Thoma MD, Anna Totzauer MD, Andrea Trenkler MD, Armin Vesenmayer MD and Jeanette Wolf MD, for data collection and for constructive inputs to improve the register.

\section{Funding}

For each CRF sent to BIOREG, BIOREG pays an allowance to the reporting centre or medical office. BIOREG pays honorarium for collecting the BIOREGCRFs and data processing to Mr Andreas Schimetta (ASKOLIF).

\section{Availability of data and materials}

BIOREG is a non-profit association for the application of bDMARDs and newly tsDMARDs in inflammatory rheumatic diseases. For data extraction or insights into evaluated data, a written request must be directed to the scientific committee of BIOREG (see $\$ 17$ of the articles of association at www.bioreg.at),

\section{Authors' contributions}

$\mathrm{BR}$ coordinated the study and $\mathrm{MH}, \mathrm{BFL}, \mathrm{FS}$ and JZ participated in its design. $B F L, J H, M H, W H, R P, B R, G E S, M S$ and JZ contributed in collecting data. All authors contributed to the interpretation of the data. BR, BFL and JZ drafted the manuscript and discussed it with all authors. All authors read and approved the final manuscript.

\section{Competing interests}

BIOREG was established by an unrestricted industrial grant (with contributions from AbbVie, Merck Sharp \& Dohme, Pfizer Corporation Austria, Roche Austria, UCB Pharma) that has no influence on the collection, analysis or publication of collected data. The authors received no specific funding for this work. JZ has received speakers fees, travel costs or advisory board fees from: AbbVie, Astro Pharma, Pfizer, MSD, BMS, Celgene, UCB, Roche, Merck.

\section{Consent for publication}

Not applicable.

\section{Ethics approval and consent to participate}

The ethical committee of Lower Austria has approved the study design of BIOREG (Reference number GS4-EK-085-2009), which is renewed annually (latest renewal January 2016). All patients gave their informed consent before inclusion into BIOREG.

\footnotetext{
Author details

'Lower Austrian State Hospital Stockerau, 2nd Department for internal medicine, Lower Austrian Center for Rheumatology, Landstrasse 18, Stockerau 2000, Austria. ${ }^{2}$ Karl Landsteiner Institute for Clinical Rheumatology, Landstrasse 18, Stockerau 2000, Austria. ${ }^{3}$ Ludwig Boltzmann Institute of Osteology at the Hanusch Hospital of WGKK and AUVA Trauma Centre Meidling, 1st Medical Department, Hanusch Hospital Vienna, Heinrich-Collinstrasse 30, Vienna 1140, Austria. ${ }^{4}$ Medical University of Innsbruck, Anichstrasse 35, Innsbruck 6020, Austria. ${ }^{5}$ BIOREG,

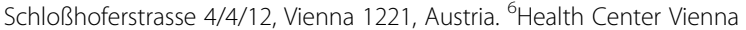
Mariahilf, Wiener Gebietskrankenkasse, Mariahilfer Strasse 85-87, Vienna 1060, Austria. 'Tyrolean State Hospital Hochzirl, Hochzirl 6170, Austria. ${ }^{8}$ Office based rheumatologist, Freistätter Strasse 16, Linz 4040, Austria. ${ }^{9}$ Office based rheumatologist, Freiung 19, Wels 4070, Austria. ${ }^{10}$ Department for Internal Medicine, Lower Austrian State Hospital Amstetten, Krankenhausstrasse 21, Amstetten 3300, Austria. ${ }^{11}$ Medical University of Graz, Auenbruggerplatz 2, Graz 8010, Austria.
}

Received: 19 June 2016 Accepted: 5 August 2016 Published online: 22 August 2016

\section{References}

1. BIOREG Website [Internet. Accessed 31 May 2016]. [Website in German] Available from: http://www.bioreg.at/

2. RABBIT Website [Internet. Accessed 31 May 2016]. [Website in German and English] Available from: http://www.biologika-register.de/home/

3. Prevoo ML, van't Hof MA, Kuper $H H$, van Leeuwen MA, van de Putte $L B$, van Riel PL. Modified disease activity scores that include twenty-eight-joint counts: development and validation in a prospective longitudinal study of patients with rheumatoid arthritis. Arthritis Rheum. 1995;38:44-8.

4. Leeb BF, Haindl PM, Maktari A, Nothnagl T, Rintelen B. Patient-centered rheumatoid arthritis disease activity assessment by a modified RADAI. J Rheumatol. 2008;35:1294-9.

5. Fries JF, Spitz PW, Kraines RG, Holman HR. Measurement of patient outcome in arthritis. Arthritis Rheum. 1980;23:137-45.

6. Fransen J, Creemers MC, Van Riel PL. Remission in rheumatoid arthritis: agreement of the disease activity score (DAS28) with the ARA preliminary remission criteria. Rheumatology (Oxford). 2004;43:1252-5.

7. Felson DT, Smolen JS, Wells G, Zhang B, van Tuyl LH, Funovits J, American College of Rheumatology, European League Against Rheumatism, et al. American College of Rheumatology/European League Against Rheumatism provisional definition of remission in rheumatoid arthritis for clinical trials. Arthritis Rheum. 2011;63:573-86.

8. Rintelen B, Haindl PM, Sautner J, Leeb BA, Deutsch C, Leeb BF. The rheumatoid arthritis disease activity index-5 in daily use. Proposal for disease activity categories. J Rheumatol. 2009;36:918-24.

9. van Gestel AM, Prevoo ML, van't Hof MA, van Rijswijk MH, van de Putte LB, van Riel PL. Development and validation of the European League Against Rheumatism response criteria for rheumatoid arthritis. Comparison with the preliminary American College of Rheumatology and the World Health Organization/International League Against Rheumatism Criteria. Arthritis Rheum. 1996:39:34-40.

10. Rintelen B, Sautner J, Schwarzenfeld C, Haindl PM, Leeb BA, Leeb BF. Proposals for thresholds to express improvement and detoriation in rheumatoid arthritis patients according to the RADAI-5 [Abstract]. Ann Rheum Dis Suppl. 2009;68 Suppl 3:221.

11. Rintelen B, Sautner J, Haindl P, Mai H, Brezinschek HP, Leeb BF. Remission in rheumatoid arthritis: a comparison of the 2 newly proposed ACR/EULAR remission criteria with the rheumatoid arthritis disease activity index-5, a patient self-report disease activity index. J Rheumatol. 2013;40:394-400.

12. Shahouri SH, Michaud K, Mikuls TR, Caplan L, Shaver TS, Anderson JD, et al. Remission of rheumatoid arthritis in clinical practice: application of the American College of Rheumatology/European League Against Rheumatism 2011 remission criteria. Arthritis Rheum. 2011;63:3204-15.

13. Prince FH, Bykerk VP, Shadick NA, Lu B, Cui J, Frits M, et al. Sustained rheumatoid arthritis remission is uncommon in clinical practice. Arthritis Res Ther. 2012;14(2):R68.

14. Kearsley-Fleet L, Závada J, Hetland ML, Nordström DC, Aaltonen KJ, Listing J, EULAR Study Group for Registers and Observational Drug Studies, et al. The EULAR Study Group for Registers and Observational Drug Studies: comparability of the patient case mix in the European biologic disease modifying anti-rheumatic drug registers. Rheumatology (Oxford). 2015:54:1074-9.

15. Uhlig T, Lie E, Norvang V, Lexberg ÅS, Rødevand E, Krøll F, et al. Achievement of Remission and Low Disease Activity Definitions in Patients with Rheumatoid Arthritis in Clinical Practice: Results from the NOR-DMARD Study. J Rheumatol. 2016;43(4):716-23.

16. Listing J, Strangfeld A, Rau R, Kekow J, Gromnica-Ihle E, Klopsch T, et al. Clinical and functional remission: even though biologics are superior to conventional DMARDs overall success rates remain low-results from RABBIT, the German biologics register. Arthritis Res Ther. 2006;8(3):R66.

17. Initiative Arznei und Vernunft [Internet. Accessed 21 Nov 2015]. [Article in German] Available from: http://www.pharmig.at/uploads/ AVLeitlinieRheumatoideArthritis_7873_DE.pdf

18. Smolen JS, Landewé R, Breedveld FC, Buch M, Burmester G, Dougados M, et al. EULAR recommendations for the management of rheumatoid arthritis with synthetic and biological disease-modifying antirheumatic drugs: 2013 update. Ann Rheum Dis. 2014;73:492-509.

19. lannone F, Gremese E, Gallo G, Sarzi-Puttini P, Botsios C, Trotta F, GISEA (Gruppo Italiano Studio Early Arthritis), et al. High rate of disease remission in moderate rheumatoid arthritis on etanercept therapy: data from GISEA, the Italian biologics register. Clin Rheumatol. 2014;33:31-7. 
20. Listing J, Gerhold K, Zink A. The risk of infections associated with rheumatoid arthritis, with its comorbidity and treatment. Rheumatology (Oxford). 2013;52:53-61.

21. Strangfeld A, Eveslage $M$, Schneider $M$, Bergerhausen $H J$, Klopsch $T$, Zink A, et al. Treatment benefit or survival of the fittest: what drives the time-dependent decrease in serious infection rates under TNF inhibition and what does this imply for the individual patient? Ann Rheum Dis. 2011;70:1914-20.

22. Listing J, Strangfeld A, Kary S, Rau R, von Hinueber U, Stoyanova-Scholz M, et al. Infections in patients with rheumatoid arthritis treated with biologic agents. Arthritis Rheum. 2005;52(11):3403-12.

23. Singh JA, Cameron C, Noorbaloochi S, Cullis T, Tucker M, Christensen R, et al. Risk of serious infection in biological treatment of patients with rheumatoid arthritis: a systematic review and meta-analysis. Lancet. 2015; 386(9990):258-65.

24. Michaud TL, Rho YH, Shamliyan T, Kuntz KM, Choi HK. The comparative safety of tumor necrosis factor inhibitors in rheumatoid arthritis: a metaanalysis update of 44 trials. Am J Med. 2014;127(12):1208-32.

25. Ramiro S, Gaujoux-Viala C, Nam JL, Smolen JS, Buch M, Gossec L, van der Heijde D, Winthrop K, Landewé R. Safety of synthetic and biological DMARDs: a systematic literature review informing the 2013 update of the EULAR recommendations for management of rheumatoid arthritis. Ann Rheum Dis. 2014;73(3):529-35.

26. Singh JA, Wells GA, Christensen R, Tanjong Ghogomu E, Maxwell L, Macdonald JK, et al. Adverse effects of biologics: a network meta-analysis and Cochrane overview. Cochrane Database Syst Rev. 2011;2:CD008794.

27. Buttgereit F. Do the treatment with glucocorticoids and/or the disease itself drive the impairment in glucose metabolism in patients with rheumatoid arthritis? Ann Rheum Dis. 2011;70:1881-3.

28. Listing J, Kekow J, Manger B, Burmester GR, Pattloch D, Zink A, et al. Mortality in rheumatoid arthritis: the impact of disease activity, treatment with glucocorticoids, TNFa inhibitors and rituximab. Ann Rheum Dis. 2015;74:415-21.

29. van der Goes MC, Jacobs JW, Boers M, Andrews T, Blom-Bakkers MA, Buttgereit $F$, et al. Patient and rheumatologist perspectives on glucocorticoids: an exercise to improve the implementation of the European League Against Rheumatism (EULAR) recommendations on the management of systemic glucocorticoid therapy in rheumatic diseases. Ann Rheum Dis. 2010;69(6):1015-21.

30. Da Silva JAP, Jacobs JWG, Kirwan JR, Boers M, Saag KG, Ines LBS, et al. Safety of low dose glucocorticoid treatment in rheumatoid arthritis: published evidence and prospective trial data. Ann Rheum Dis. 2006;65(3):285-93.

31. Herold M, Eichbauer-Sturm G, Puchner R, Rintelen B, Singer F, Leeb B. Common place though not approved - Monotherapy with biologics. Data from the Austrian BIOREG registry [Abstract]. Ann Rheum Dis Suppl. 2015;74 Suppl 2:486.

32. Jørgensen TS, Kristensen LE, Christensen R, Bliddal H, Lorenzen T, Hansen MS, et al. Effectiveness and drug adherence of biologic monotherapy in routine care of patients with rheumatoid arthritis: a cohort study of patients registered in the Danish biologics registry. Rheumatology (Oxford). 2015; 54(12):2156-65.

33. Gabay C, Riek M, Scherer A, Finckh A, SCQM collaborating physicians. Effectiveness of biologic DMARDs in monotherapy versus in combination with synthetic DMARDs in rheumatoid arthritis: data from the Swiss Clinical Quality Management Registry. Rheumatology (Oxford). 2015;54(9):1664-72.

34. van Vollenhoven RF, Geborek P, Forslind K, Albertsson K, Ernestam S, Petersson IF, Swefot study group, et al. Conventional combination treatment versus biological treatment in methotrexate-refractory early rheumatoid arthritis: 2 year follow-up of the randomised, non-blinded, parallel-group Swefot trial. Lancet. 2012;379(9827):1712-20.

35. Moreland LW, O'Dell JR, Paulus HE, Curtis JR, Bathon JM, St Clair EW, TEAR Investigators, et al. A randomized comparative effectiveness study of oral triple therapy versus etanercept plus methotrexate in early aggressive rheumatoid arthritis: the treatment of Early Aggressive Rheumatoid Arthritis Trial. Arthritis Rheum. 2012;64(9):2824-35.

36. Eriksson JK, Wallman JK, Miller H, Petersson IF, Ernestam S, Vivar N, van Vollenhoven RF, Neovius M. Infliximab versus Conventional Combination Treatment and 7-Year Work Loss in Early RA: Results of the Randomized Swefot Trial. Arthritis Care Res (Hoboken). 2016. doi: 10.1002/acr.22899

37. Eriksson JK, Karlsson JA, Bratt J, Petersson IF, van Vollenhoven RF, Ernestam $S$, et al. Cost-effectiveness of infliximab versus conventional combination treatment in methotrexate-refractory early rheumatoid arthritis: 2-year results of the register-enriched randomised controlled SWEFOT trial. Ann Rheum Dis. 2015;74(6):1094-101.

38. Austria-Codex Fachinformation, Erscheindatum 01.01.2015, Apothekerverlag, [Internet. Accessed 30 Oct 2015]. [Website in German] Available from: http// www.apoverlag.at

39. Putrik P, Ramiro S, Kvien TK, Sokka T, Uhlig T, Boonen A, Equity in Clinical Eligibility Criteria for RA treatment Working Group. Variations in criteria regulating treatment with reimbursed biologic DMARDs across European countries. Are differences related to country's wealth? Ann Rheum Dis. 2014; 73(11):2010-21.

40. Vermeer M, Kievit W, Kuper HH, Braakman-Jansen LM, Bernelot Moens HJ, et al. Treating to the target of remission in early rheumatoid arthritis is cost-effective: results of the DREAM registry. BMC Musculoskelet Disord. 2013;14:350.

41. Moghadam MG, Vonkeman HE, Ten Klooster PM, Tekstra J, van Schaardenburg D, Starmans-Kool M, Dutch National POET Collaboration et al. Stopping tumor necrosis factor-inhibitors in patients with established rheumatoid arthritis in remission or stable low disease activity: a pragmatic randomized multicenter open-label controlled trial. Arthritis Rheumatol. 2016. doi: 10.1002/art.39626

42. van Herwaarden N, den Broeder AA, Jacobs W, van der Maas A, Bijlsma JW, van Vollenhoven RF, et al. Down-titration and discontinuation strategies of tumor necrosis factor-blocking agents for rheumatoid arthritis in patients with low disease activity. Cochrane Database Syst Rev. 2014;9:CD010455. doi:10.1002/14651858.CD010455.pub2.

43. Fleischmann R, Kavanaugh A, Smolen J. Methodological aspects and the interpretation of clinical trial data: lessons from the TEAR trial. Rheumatology. 2013;52:409-10.

\section{Submit your next manuscript to BioMed Central and we will help you at every step:}

- We accept pre-submission inquiries

- Our selector tool helps you to find the most relevant journal

- We provide round the clock customer support

- Convenient online submission

- Thorough peer review

- Inclusion in PubMed and all major indexing services

- Maximum visibility for your research

Submit your manuscript at www.biomedcentral.com/submit
BioMed Central 